Cita bibliográfica: De Lima, F, Cappellano Dos Santos, M. M. y Köche, J. C. (2020). Turismo pedagógico ou Atividade pedagógica pelo turismo? O binômio «turismo pedagógico»: concepções de turismo e pressupostos epistemológico-pedagógicos subjacentes. Investigaciones Turísticas (19), pp.139-162.https://doi.org/10.14198/INTURI2020.19.07

\title{
Turismo pedagógico ou Atividade pedagógica pelo turismo? O binômio "turismo pedagógico»: concepções de turismo e pressupostos epistemológico-pedagógicos subjacentes
}

\author{
¿Turismo pedagógico o Actividad pedagógica por el turismo? El binomio «turismo \\ pedagógico»: concepciones de turismo y presupuestos epistemológico-pedagógicos \\ subyacentes
}

Pedagogical tourism or pedagogical activity through tourism? The binomial «pedagogical tourism ": tourism conceptions and underlying epistemological-pedagogical assumptions

Francielle De Lima iD, Universidade Federal do Pampa, Brasil

flimatur1264@gmail.com

Marcia Maria Cappellano Dos Santos (iD, Universidade de Caxias do Sul, Brasil mcsantos@ucs.br

Jose Carlos Köche (iD, Universidade de Caxias do Sul, Brasil

jckoche@ucs.br

\section{RESUMO}

Este artigo, resultado de pesquisa de cunho exploratório bibliográfico, tem como objeto de estudo o conceito de Turismo Pedagógico (TP) depreendido de artigos publicados em periódicos científicos brasileiros e/ou apresentados em eventos científicos consolidados na área do Turismo, no período de 2005 a 2017. Com uma abordagem hermenêutica, focaliza relações conceituais que emergem da análise desse binômio, considerando o fato de "turismo" configurar-se como termo nuclear da expressão. Busca assim responder à questão: Na adjetivação do turismo como pedagógico, que concepções de turismo e que pressupostos epistemológico-pedagógicos estariam aí subjacentes? A análise textual leva a uma discussão conceitual sobre a própria denominação da atividade no âmbito escolar, trazendo à reflexão, na relação binomial, o caráter contingencial do pedagógico ou este como característica substantiva do turismo.

Palavras-chave: Turismo; Turismo pedagógico; Configurações conceituais; Pressupostos epistemológico-pedagógicos. 


\section{RESUMEN}

Este artículo, resultado de investigación de tipo exploratorio bibliográfico, tiene como objeto de estudio el concepto de Turismo Pedagógico (TP) resultante de artículos publicados en periódicos científicos brasileños y/o presentados en eventos científicos consolidados en el área de Turismo, en el periodo de 2005 a 2017. Con un planteamiento hermenéutico, enfoca las relaciones conceptuales que surgen del análisis de ese binomio, considerando el hecho de que "turismo» se configura como término nuclear de la expresión. Se trata de responder a la pregunta: En la adjetivación del turismo como pedagógico, ¿qué concepciones de turismo y qué presupuestos epistemológico-pedagógicos estarían allí subyacentes? El análisis textual lleva a una discusión conceptual sobre la propia denominación de la actividad en el ámbito escolar, trayendo la reflexión, en la relación binomial, sobre el carácter contingencial de lo pedagógico o éste como característica sustantiva del turismo.

Palabras clave: Turismo; Turismo pedagógico; Configuraciones conceptuales; Presupuestos epistemológico-pedagógicos.

\section{ABSTRACT}

Using a bibliographical exploratory research approach, this article studies the concept of pedagogical tourism (PT), drawing from articles published in Brazilian journals and/or presented at well-established scientific events in the Tourism area, between the years 2005 and 2017. Based on a hermeneutic approach, it focuses on the conceptual relations which emerge from the analysis of the binomial, considering that tourism itself constitutes the nuclear term of the expression. Thus, it seeks to answer the question: In the process of attributing adjectives to tourism, which underlying conceptions of tourism and epistemological-pedagogical assumptions would be present? The textual analysis leads to a conceptual discussion about the very denomination of the activity within the school context, reflecting within the binomial relation, on the contingency nature of the pedagogical or the pedagogical aspect as a substantive characteristic of tourism.

Keywords: Tourism; Pedagogical tourism; Conceptual configurations; Epistemologicalpedagogical assumptions.

\section{CONSIDERAÇÕES INTRODUTÓRIAS}

A pesquisa sobre a qual versa o presente artigo tem como elemento desencadeador experiências empíricas dos pesquisadores na função docente e administrativa envolvendo planejamento e operacionalização de ações, no ensino formal (Educação Básica) denominadas usualmente pelo binômio "Turismo pedagógico» (TP), as quais se constituíam em saídas de campo. A essas experiências agregaram-se outras no âmbito acadêmico, quando, se entendeu apropriado questionar, conceitualmente, o referido binômio, ainda que preliminarmente. Contudo, questionamentos que originaram dissertação de mestrado e, posteriormente esta produção são desdobramentos da revisão de literatura empreendida e publicada em 2012 sob o título «Turismo Pedagógico e binômios considerados afins: um percurso de revisão de 
literatura», tendo por recorte espacial, produções acadêmicas do Brasil voltadas ao TP, sobre as quais se efetivaram incursões reflexivas, com a finalidade de apresentar uma sistematização dessa produção, e, mais especificamente, uma visão analítico-conceitual do entendimento que estudiosos do Turismo mostravam ter acerca do tema. Para tanto, acessaram-se publicações constantes de periódicos científicos, anais de eventos, teses, dissertações, livros, capítulos de livros, entre outras produções, abrangendo o período de 2003 a 2012. Em um universo pesquisado com mais de 5 mil trabalhos, chegou-se ao número de 47 publicações, das quais 20 abordavam explicitamente o binômio «Turismo pedagógico» e 12, binômios considerados afins.

Nessa primeira abordagem textual, a tônica recaiu sobre relatos de experiências vinculadas principalmente ao ensino formal, assim como sobre a relevância dessas atividades extraclasse e suas contribuições para a ampliação dos conhecimentos promovidos/abordados nos estabelecimentos de ensino. Desses textos depreendeu-se um conceito tácito de Turismo relacionado ao sair da rotina escolar para "aprender» o que se pretende "ensinar», fora da sala de aula. O binômio não se constituiu em objeto central de questionamento, como também não o são a própria qualificação "pedagógico», o conceito de turismo, tampouco implicações teórico-práticas subjacentes à articulação do termo nuclear (turismo) com o adjetivo (pedagógico), no referido binômio.

Especificamente quanto aos binômios considerados afins, foram identificadas, denominações associadas ao espaço (turismo rural pedagógico, estudo do meio), ao acervo-histórico-cultural (educação patrimonial), a questões ambientais (educação ambiental) e ao ensino formal (turismo estudantil, turismo educacional, saída de campo, excursão, visita técnica, aula-passeio, aula de descoberta, educação experiencial, atividade extraclasse/ extramuros).

Essa imprecisão semântica reflete-se em situações diversas, inclusive originando, em um mesmo trabalho, substituições de denominações por outras diferentes tomadas como sinônimas, ou ainda, quando consideradas diversas, empregadas sem que as respectivas especificidades caracterizadoras sejam suficiente ou claramente explícitas.

Tais constatações conduziram à percepção da necessidade de dar sequência a reflexões sobre a permeabilidade ou sobre delimitações conceituais depreendidas da coexistência daquelas designações vinculadas ao TP, de sorte que, na direção de suprir lacuna analítica que então se evidenciava, retomou-se o estudo precedente, ampliou-se o arco temporal (até 2017), optou-se por restringir o corpus a artigos publicados em periódicos científicos e em anais de eventos (pelo entendimento de que se trata de publicações que encerram maior dinamicidade na divulgação da produção científica) e estabeleceram-se outros recortes metodológicos, conforme detalhados no próximo item. Em assim sendo, o presente artigo - que dá a conhecer o processo de investigação que dali decorreu - versa sobre o conceito de TP, focalizado em relações conceituais emergentes da análise desse binômio, considerando particularmente o fato de "turismo" configurar-se como termo nuclear da expressão. Objetiva identificar/explicitar configurações conceituais que assume a denominação «Turismo pedagógico» em proposições teóricas ou teórico-práticas presentes e acessadas na literatura científica em que é tematizado o TP, considerando, de um lado, abordagens conceituais de turismo e, de outro, relações que 
se estabelecem entre modelos epistemológicos e pedagógicos. Dito de outra forma, tem-se, resumidamente, o objetivo de encontrar resposta às questões: Que pedagógico é esse e que turismo é esse subjacentes ao binômio «Turismo pedagógico»?

Como referentes analíticos conceituais básicos para Turismo são trazidos, dentre outras abordagens: a) as de Beni (2008) e Lohmann e Panosso Netto (2012), no que tange à dimensão mercadológica; b) a de Perazzolo, Santos e Pereira (2013), no que concerne à dimensão relacional vinculada à escola. Quanto aos modelos epistemológicos, recorreu-se a Köche (2010), Kuhn (2003) e Behrens (1999), focalizando paradigmas da ciência moderna e contemporânea. Já, com relação aos modelos epistemológico-pedagógicos, utilizaram-se as proposições teóricas de Piaget (1983), Vygotsky (1979) e Becker (2012).

Face a restrições editoriais de extensão, essas perspectivas teóricas serão posteriormente desdobradas no item Síntese interpretativa: cruzando resultados e perspectivas teóricas.

\section{CAMINHOS METODOLÓGICOS PERCORRIDOS}

Como mencionado, a pesquisa, de caráter exploratório-bibliográfico, abrange o período de 2005 a $2017^{1}$. Nos dizeres de Köche (2010, p.126), quando não se dispõe ainda de um sistema de teorias e conhecimentos desenvolvidos a respeito de fenômenos e problemas, «é necessário desencadear um processo de investigação que identifique a natureza do fenômeno e aponte as características essenciais das variáveis que se quer estudar». $\mathrm{Na}$ presente investigação, esse processo toma forma a partir de incursões em fontes bibliográficas disponíveis e acessadas.

Os textos foram selecionados observadas etapas e critérios a seguir descriminados:

a. Artigos cujos títulos explicitamente apresentavam o binômio "TP», acessados via Portal de Periódicos da Coordenação de Aperfeiçoamento de Pessoal de Nível Superior - CAPES², critério esse que levou em conta o quesito de estruturação textual segundo o qual os termos do título devem encerrar o foco central da produção, na medida em que se constitui no elemento principal para nortear a leitura e criar espectativas sobre o conteúdo do texto;

1. A análise dos artigos publicados no arco temporal de 2005 ao primeiro semestre de 2012 foi objeto da referida dissertação de Mestrado.

2. A Coordenação de Aperfeiçoamento de Pessoal de Nível Superior (CAPES), fundação do Ministério da Educação (MEC), desempenha papel fundamental na expansão e consolidação da pós-graduação stricto sensu (mestrado e doutorado) em todos os estados brasileiros. Entre suas linhas de ação estão: avaliação da pós-graduação stricto sensu; investimentos na formação de recursos de alto nível no país e no exterior; promoção da cooperação científica internacional; acesso e divulgação da produção científica via seu Portal de Periódicos (revistas científicas). Esse Portal consiste numa biblioteca virtual que reúne e disponibiliza a instituições de ensino e pesquisa no Brasil o melhor da produção científica internacional. Ele conta com um acervo de mais de 45 mil títulos com texto completo, 130 bases referenciais, 12 bases dedicadas exclusivamente a patentes, além de livros, enciclopédias e obras de referência, normas técnicas, estatísticas e conteúdo audiovisual. Nesse sentido, é uma ferramenta fundamental às atribuições da CAPES de fomento, avaliação e regulação dos cursos de PósGraduação e desenvolvimento da pesquisa científica no Brasil. Disponível em Portal CAPES. 
b. Seleção, entre os artigos encontrados, daqueles publicados em periódicos com avaliação Qualis ${ }^{3}$, isto é, resultante de procedimentos afetivados pela CAPES para estratificação da qualidade da produção intelectual dos Programas de Pós-graduação e, nesse sentido, permaneceram, no corpus da pesquisa, os artigos situados entre os estratos A1 e B5;

c. Artigos publicados nos anais do Seminário de Pesquisa em Turismo do Mercosul SEMINTUR e do Seminário da Associação Nacional de Pesquisa e Pós-graduação em Turismo - ANPTUR, ambos os eventos considerados os mais tradicionais na área do Turismo e, ao mesmo tempo, não concebidos a partir de um segmento turístico específico.

Aplicados os critérios estabelecidos, passaram a constituir o corpus da pesquisa 17 artigos indicados no Quadro 1:

Quadro 1. Artigos constitutivos do Corpus - período 2005-2017

\begin{tabular}{|c|c|c|c|}
\hline Fonte & Ano & Autores & Título \\
\hline \multirow[t]{3}{*}{ Global Tourism } & \multirow[t]{3}{*}{2005} & Morais, J. P.; Maia, J. S. da S. & $\begin{array}{l}\text { A prática do Turismo Pedagógico: um } \\
\text { estudo de caso na Creche E.M.E.I. Mário } \\
\text { de Andrade }\end{array}$ \\
\hline & & Raykil, E. B.; Raykil, C. & $\begin{array}{l}\text { Turismo Pedagógico: uma interface } \\
\text { diferencial no processo ensino } \\
\text { aprendizagem }\end{array}$ \\
\hline & & Peccatiello, A. F. O. & $\begin{array}{l}\text { Turismo Pedagógico como estratégia } \\
\text { de ensino-aprendizagem sob a ótica dos } \\
\text { Parâmetros Curriculares Nacionais: } 30 \text { e } \\
\text { 40 ciclos do ensino fundamental }\end{array}$ \\
\hline \multirow[t]{3}{*}{$\begin{array}{l}\text { SEMINTUR/ } \\
\text { ANPTUR }\end{array}$} & \multirow[t]{3}{*}{2006} & Moraes, C. C. de A. & $\begin{array}{l}\text { Turismo Pedagógico em Quilombos - } \\
\text { considerações sobre a formação de uma } \\
\text { comunidade turística }\end{array}$ \\
\hline & & $\begin{array}{l}\text { Silva, I. de O.; Nascimento, } \\
\text { M. C. D. }\end{array}$ & $\begin{array}{l}\text { Turismo Pedagógico: uma Estratégia } \\
\text { para o Ensino de História e Educação } \\
\text { Patrimonial }\end{array}$ \\
\hline & & $\begin{array}{l}\text { Gonçalves, J. de S.; Serafim, } \\
\text { L. S. }\end{array}$ & $\begin{array}{l}\text { O Desenvolvimento de um Novo Produto } \\
\text { Turístico: o Turismo Pedagógico }\end{array}$ \\
\hline $\begin{array}{l}\text { Caderno Virtual } \\
\text { de Turismo }\end{array}$ & 2008 & Perinotto, A. R. C. & $\begin{array}{l}\text { Turismo pedagógico: uma ferramenta } \\
\text { para educação ambiental }\end{array}$ \\
\hline SEMINTUR & 2008 & $\begin{array}{l}\text { Silveira, C. R. F. D. da; } \\
\text { Martins, P. C. S.; Sa Vieira, F. }\end{array}$ & $\begin{array}{l}\text { Turismo Pedagógico em Dourados /MS- } \\
\text { Uma atividade educacional }\end{array}$ \\
\hline
\end{tabular}

3. Qualis é o conjunto de procedimentos utilizados pela CAPES para estratificação da qualidade da produção intelectual dos programas de pós-graduação. O Qualis afere a qualidade dos artigos e de outros tipos de produção, a partir da análise da qualidade dos veículos de divulgação, ou seja, periódicos científicos. A classificação de periódicos é realizada pelas Áreas de avaliação da CAPES e passa por processo anual de atualização. Os estratos avaliativos Qualis compreendem duas ordens de qualidade, às quais correspondem a pontuações específicas: A1, A2, B1, B2 (Estratos superiores) e B3, B4 e B5 (Estratos inferiores). Quando situada no estrato C, a publicação não é pontuada. Disponível em Portal CAPES. 


\begin{tabular}{|l|c|l|l|}
\hline Visão e Ação & 2010 & Bonfim, M. V. de S. & $\begin{array}{l}\text { Por uma pedagogia diferenciada: uma } \\
\text { reflexão acerca do Turismo Pedagógico } \\
\text { como prática educativa }\end{array}$ \\
\hline SEMINTUR & 2010 & Ito, C. A. & $\begin{array}{l}\text { Turismo Pedagógico: Relato de } \\
\text { Experiência no Ensino Fundamental }\end{array}$ \\
\hline $\begin{array}{l}\text { Turismo e } \\
\text { Sociedade }\end{array}$ & 2012 & $\begin{array}{l}\text { Gomes, D. S.; Mota, K. M.; } \\
\text { Perinotto, A. R. C. }\end{array}$ & $\begin{array}{l}\text { Turismo pedagógico como ferramenta } \\
\text { de educação patrimonial: a visão dos } \\
\text { professores de História em um colégio } \\
\text { estadual de Parnaíba (Piauí, Brasil) }\end{array}$ \\
\hline SEMINTUR & 2012 & Matos, F. de C. & $\begin{array}{l}\text { Turismo pedagógico: o estudo do meio } \\
\text { como ferramenta fomentadora do } \\
\text { currículo escolar }\end{array}$ \\
\hline SEMINTUR & 2012 & $\begin{array}{l}\text { Lima, F. de; Santos M. M. C; } \\
\text { Rejowski, M. }\end{array}$ & $\begin{array}{l}\text { Turismo Pedagógico e binômios } \\
\text { considerados afins: um percurso de } \\
\text { revisão de literatura }\end{array}$ \\
\hline ANPTUR & 2012 & $\begin{array}{l}\text { Tonini, H.; Ferreira, M. V.; } \\
\text { Nunes, M. B. }\end{array}$ & $\begin{array}{l}\text { Turismo Pedagógico na Restinga (Porto } \\
\text { Alegre, RS) }\end{array}$ \\
\hline $\begin{array}{l}\text { Revista } \\
\text { Turismo \& } \\
\text { desenvolvimento }\end{array}$ & 2014 & Alves, K. dos S. & $\begin{array}{l}\text { O turismo pedagógico como indutor } \\
\text { de lugares identitários para reconhecer, } \\
\text { interpretar e preservar }\end{array}$ \\
\hline ANPTUR & 2016 & $\begin{array}{l}\text { Valduga, V.; Fernandes, A. do } \\
\text { R. A. }\end{array}$ & $\begin{array}{l}\text { Turismo Pedagógico: uma práxis } \\
\text { transdisciplinar entre o turismo e a } \\
\text { pedagogia }\end{array}$ \\
\hline Applied Tourism & 2017 & $\begin{array}{l}\text { Carvalho, A. B. P.; Escobar, L. } \\
\text { O. C.; Cademartori, C. V. }\end{array}$ & $\begin{array}{l}\text { A educação ambiental através do turismo } \\
\text { pedagógico }\end{array}$ \\
\hline
\end{tabular}

Fonte: Elaborado pelos autores, 2019.

Na medida em que o cerne dos objetivos da pesquisa institui-se na identificação de significados explícitos de TP ou na depreensão de sentidos subjacentes a configurações conceituais que assume o binômio, o traçado metodológico passa a requerer uma abordagem interpretativa (hermenêutica). Busca-se assim ultrapassar compreensões imediatas, ou pré-compreensões.

Poder-se-ia dizer, tomando emprestadas as palavras de Ricoeur (1978), que identificar significados explícitos e depreender sentidos subjacentes que identifiquem/explicitem configurações conceituais que assume a denominação «TP» em proposições teóricas ou teórico-práticas presentes e acessadas na literatura científica, requer que sejam desdobrados níveis de significação implicados na significação literal dos textos selecionados para constituir o corpus da pesquisa. Para tanto, foram definidas algumas estratégias de abordagem textual que pudessem, a partir da leitura literal, encaminhar aos processos de análise (desconstrução) e de interpretação (reconstrução ou síntese interpretativa).

Sob essa perspectiva e tendo em conta o fato de o foco analítico recair sobre o universo conceitual de TP, portanto, sobre o entendimento dos estudiosos em relação a Turismo, educação e pedagógico aí presentes (explícita ou implicitamente), a desconstrução textual, de forma inovadora, orientou-se, em linhas gerais, pelo processo definitório, como o apresenta 
Garcia (2006, p. 334), isto é, como um modus sciendi, no qual a definição se traduz como uma proposição predicativa constituída de quatro elementos:

Termo (definiendum) - a coisa a ser definida;

Cópula - verbo «ser» (ou seu equivalente em estruturas menos rígidas, como, por exemplo, "consistir em», "significar»);

Gênero (genus) - a classe (ou ordem) de coisas a que pertence o Termo;

Diferenças (differentiae) - tudo aquilo que distingue a coisa representada pelo Termo de outras coisas incluídas na mesma classe.

Em síntese, a proposição definitória poderia ser expressa pela seguinte fórmula:

$$
T=G+d^{1}+d^{2} \ldots d n
$$

Essa orientação deu origem a diagramas representativos da desconstrução textual, os quais foram desenhados de modo a demarcar o binômio na intersecção dos contextos do Turismo e da Educação e dar destaque, particularmente, ao Gênero (Genus) e às diferenças (differentiae), por meio dos quais se configuraria o entendimento, em cada texto, desses elementos. Com base nesse procedimento, desenvolveu-se uma síntese do processo analítico, permitindo construir, sob esse prisma, uma visão global do corpus, assim como, na sequência, desencadear a elaboração da síntese interpretativa almejada, no sentido de depreender concepções de turismo e pressupostos epistemológico-pedagógicos que estariam subjacentes ao emprego do referido binômio.

\section{ANÁLISE DO CORPUS: DESCONSTRUÇÃO TEXTUAL DIAGRAMADA}

A leitura analítica de cada um dos artigos desenvolve-se a partir de diagramas representativos da desconstrução textual realizada, seguida de uma síntese desse processo. Nesses diagramas, a coluna central relativa ao TP se situa na interface entre Turismo e Educação, subentendendo-se que a promoção intencional dos processos de aprendizagem se insere na busca do desenvolvimento integral do sujeito (ou seja, seu desenvolvimento educacional), o que supõe aprendizagens conceituais, procedimentais e atitudinais. Nesse sentido, observada a colorimetria, as colunas laterais estão nas cores vermelho e azul (cores primárias), e a central, na cor roxa (cor secundária). Nas colunas referentes ao Turismo e à Educação, estão inseridas apenas definições com Gêneros e/ou elementos diferenciadores explicitamente presentes nos textos.

Sempre tomando por base o processo definitório conforme Garcia (2006), o sinalizador $(\bullet)$ assinala as referências ao Termo em análise que apresentem um Gênero explícito com adjetivação configuradora de nível classificatório, favorecedor da distinção do Termo em relação a outros. As adjetivações entre parênteses, destacadas com a cor rosa e que passam a integrar o Gênero, são inferências com base nos elementos caracterizadores, a fim de estabelecer um padrão estrutural para a elaboração do Quadro Global (Gênero/complemento) que dá sequência ao processo de leitura analítica expressa nos diagramas. 
Já o sinalizador $(>)$ destaca as incidências do mesmo Gênero no texto. Essa diferenciação de sinalizadores permite visualizar rapidamente o número de vezes em que os Gêneros são mencionados no texto.

O sinalizador (*) representa qualificações referentes ao Termo, sem identificação direta explícita do Gênero.

Ainda, cabe destacar que todas as citações bibliográficas ou vozes outras que não a do autor dos textos são identificadas entre parênteses.

Tem-se a seguir, a título ilustrativo, a diagramação analítica do texto 7, representativa das demais análises efetivadas (Figura 1), seguida de considerações sobre elementos textuais ali presentes - às quais se reportará nas sínteses interpretativas.

Figura 1. Análise diagramada (Texto 7)

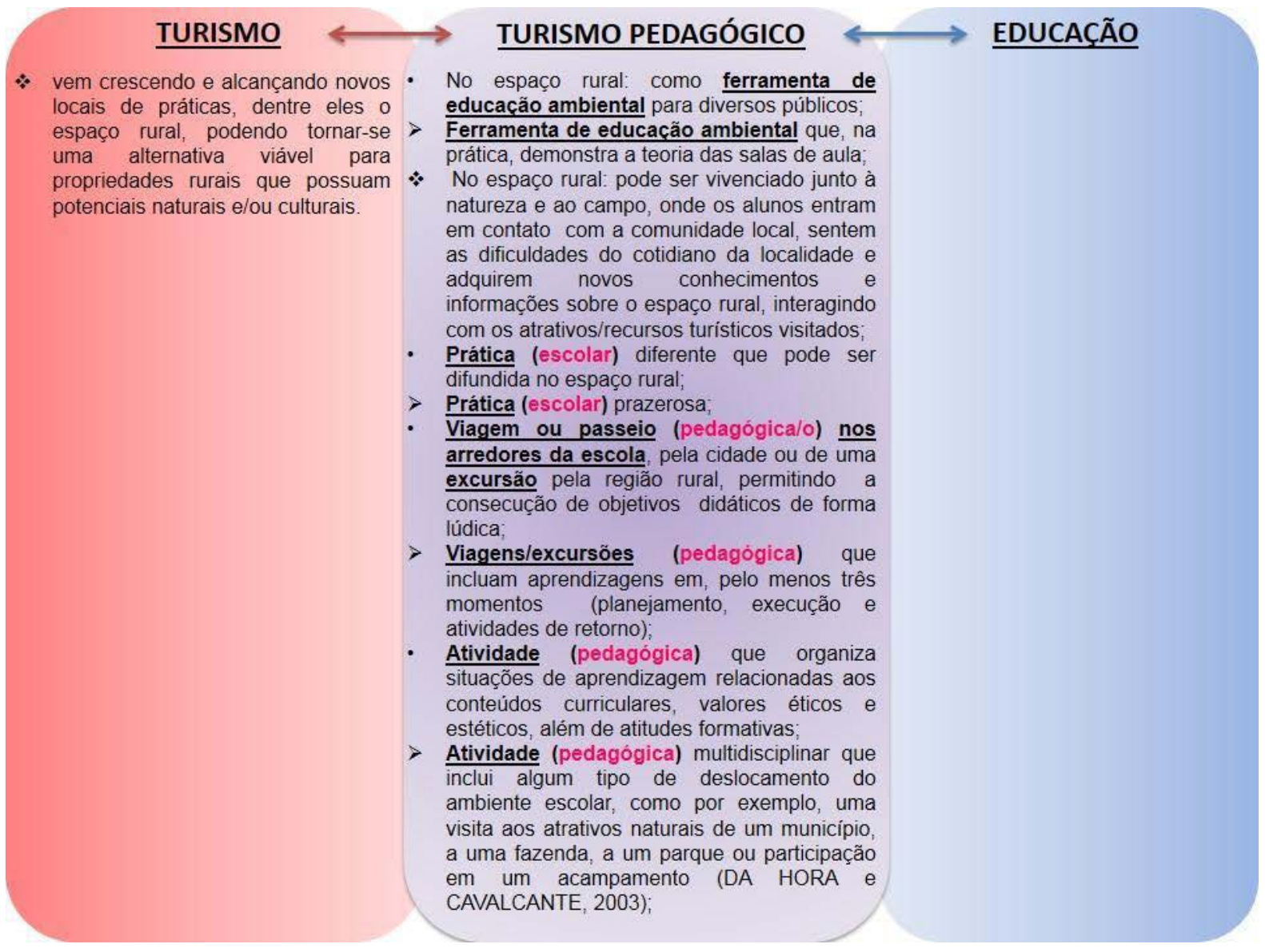




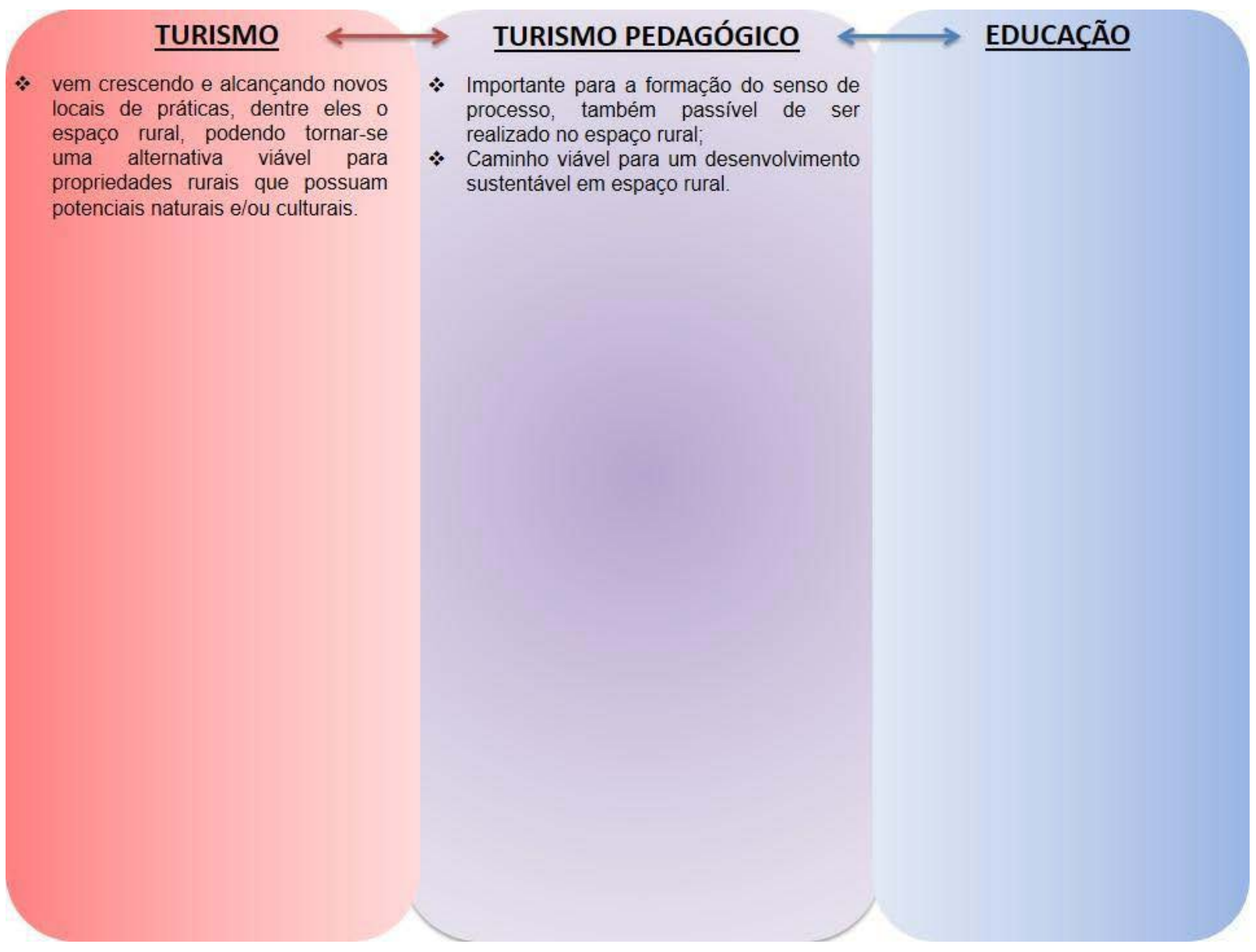

Fonte: LIMA, 2014.

\section{Lendo o diagrama:}

O texto 7 aborda três grupos conceituais: turismo rural, TP e TP no espaço rural.

No título, tem-se o TP vinculado à educação ambiental, sendo que, no resumo, esse vínculo vem atrelado à realização do TP no espaço rural. O Gênero "ferramenta» imprime a marca da funcionalidade na definição de TP no espaço rural. Essa funcionalidade é apresentada, de um lado, como "caminho viável para um desenvolvimento sustentável em espaço rural»; de outro, como "ferramenta de educação ambiental que, na prática, demonstra a teoria das salas de aula».

O turismo rural em si compreende, nos termos do autor, atividades de lazer e entretenimento, que possibilitam o contato com o cotidiano no campo, despreocupação de quem o pratica e a convivência em paz com a natureza e o ar puro. E o TP aí se insere como uma das alternativas turísticas.

O TP, de modo global, é marcado como "[...] uma prática escolar prazerosa», como recurso para o "professor atingir seus objetivos didáticos de forma lúdica, pois as atividades pedagógicas são desenvolvidas com brincadeiras e entretenimento», o que sempre inclui 
algum tipo de deslocamento (viagem, passeio - referindo-se "[...] aos arredores da escola e à cidade» - e excursão pela região rural»), todos eles Gêneros definitórios de TP,

Outro aspecto interessante a sublinhar é o destinatário do TP no espaço rural: no resumo, identificado como "diversos públicos»; ao longo do texto, restrito ao público escolar.

Merece igualmente destaque o fato de que, novamente, a sala de aula vem caracterizada como espaço de estudo teórico. Chama também atenção o aspecto paradoxal entre a racionalidade lógica própria ao processo de «demonstrar» (termo atribuído ao papel do TP) e a ludicidade com que esse se desenvolveria.

O TP, conforme o autor, implica trabalho conjunto de professores de diferentes áreas e de bacharéis em Turismo.

\section{RESULTADOS: DEFINIÇÕES DE TP EXPLÍCITAS E DEPREENDIDAS}

A análise de cada um dos textos que compõem o corpus deu lugar a uma leitura analítica global, em que se identificam e categorizam os gêneros nucleadores do conjunto das definições, o mesmo sendo realizado, na sequência, para as características definitórias diferenciadoras.

\subsection{Gêneros nucleadores das definições}

Retomando o objetivo de identificar configurações conceituais que assume a denominação "TP» e, nelas, abordagens conceituais de Turismo e relações que se estabelecem entre modelos epistemológicos e pedagógicos, tem-se uma síntese global desse processo, conforme expressa o Quadro 2. Este põe em destaque fundamentalmente os Gêneros expressos para o binômio "TP» (textualmente ou por inferência adjetivados no sentido de obtenção de nível classificatório favorecedor da distinção do Termo com relação a outros), suas incidências, suas relações, suas diferenças. Ao mesmo tempo, esse mapeamento propicia, por aproximações semânticas entre os Gêneros, o respectivo enquadramento em quatro planos ou unidades ideativas: o da Ação, o Funcional-projetivo, o Funcional-estratégico e o Econômico. 
Quadro 2. Gêneros nucleadores das definições de TP explícitos ou depreendidos dos textos e respectivo enquadramento no Plano da Ação, no Funcional-projetivo, no Funcional-

instrumental e no Econômico

\begin{tabular}{|c|c|}
\hline Gêneros Nucleadores & Planos/Número de Gêneros \\
\hline Segmento da atividade turística; de mercado; turístico. & \multirow{3}{*}{$\begin{array}{l}\text { Plano econômico } \\
\text { (13) }\end{array}$} \\
\hline Vertente do segmento turístico. & \\
\hline $\begin{array}{l}\text { Tipo de turismo; de serviço; modalidade de turismo; novo produto } \\
\text { turístico; rama del turismo. }\end{array}$ & \\
\hline $\begin{array}{l}\text { Atividade curricular; educativa/educacional; educativo-turística; } \\
\text { extraclasse; fonte de conhecimento; pedagógica; pedagógica } \\
\text { extraescolar; didático-pedagógica extraclasse; turística; Ação } \\
\text { estratégica; Aula extraclasse. }\end{array}$ & \multirow{3}{*}{$\begin{array}{l}\text { Plano da ação } \\
\text { (39) }\end{array}$} \\
\hline $\begin{array}{l}\text { Viagem como instrumento pedagógico; de cunho educacional/ } \\
\text { educativo; de estudo; viagem/passeio/excursão pedagógica; turística; } \\
\text { Estudo do meio. }\end{array}$ & \\
\hline $\begin{array}{l}\text { Prática de desenvolvimento pessoal; de ensino; de facilitação } \\
\text { educacional; de organização de viagens culturais; educativa/ } \\
\text { educacional; escolar; pedagógica. }\end{array}$ & \\
\hline Recurso metodológico; pedagógico; & \multirow{3}{*}{$\begin{array}{l}\text { Plano funcional- } \\
\text { instrumental } \\
\quad(12)\end{array}$} \\
\hline $\begin{array}{l}\text { Ferramenta de educação ambiental; de gestão; didática; educativa; } \\
\text { pedagógica. }\end{array}$ & \\
\hline Instrumento de alfabetização cultural; pedagógico. & \\
\hline $\begin{array}{l}\text { Estratégia de educação patrimonial; de ensino-aprendizagem; } \\
\text { metodológica; pedagógica; Método de ensino; Processo de educação } \\
\text { patrimonial. }\end{array}$ & $\begin{array}{l}\text { Plano funcional-projetivo } \\
\text { (9) }\end{array}$ \\
\hline
\end{tabular}

Fonte: Elaborado pelos autores, 2019.

Considerados os referidos Planos, o foco analítico especificamente no que se refere a Gênero, numa leitura global das configurações conceituais presentes nos textos em relação ao TP, evidencia o gênero como ação que educa/promove aprendizagens; como meio utilizado na consecução da ação (educacional/pedagógica; gestão pública); como uma forma de projeção de futuro (num processo que envolve decisões sobre procedimentos e resultados educacionais e pedagógicos); e também como uma ação afeta ao mercado. Ressalta-se ainda a ênfase à esfera educacional-pedagógica e, nela, ao Plano da ação.

Por outro lado, quando se observa a distribuição dos Gêneros no conjunto dos textos, tendo em conta a ocorrência desses, alguns dados chamam a atenção: excluindo somente um texto, todos os demais apresentam, cada um, no mínimo, 3 e, no máximo, 15 Gêneros diferentes, ao que vem somar-se o fato de, nos mesmos textos, os Gêneros penderem ora para a dimensão do Turismo, ora para a dimensão da Educação. Relativamente, pois, aos Gêneros em si, identifica-se uma certa «fluidez» nas configurações conceituais de TP inter e intratextos. 


\subsection{Características diferenciadoras na definição de TP}

No marco do processo definitório segundo Garcia (2006), aos Gêneros agregam-se características (differentiae) que permitem diferenciar o Termo (Definiendum) de outros. As considerações que seguem expressam, resumidamente, aspectos relativos às características diferenciadoras encontradas (tendo por base as análises textuais diagramadas).

Numa primeira incursão analítica, a associação de características aos Gêneros (em seu termo nuclear) e aos Planos em que se enquadram, dá origem ao Quadro 3:

Quadro 3. Incidência de características associadas aos termos nucleares dos Gêneros

\begin{tabular}{|l|c|c|}
\hline \multicolumn{1}{|c|}{ Gêneros (Termos nucleares) } & Plano & $\begin{array}{c}\text { Incidência de } \\
\text { características } \\
\text { diferenciadoras }\end{array}$ \\
\hline Segmento, Vertente, Tipo, Modalidade Produto, Rama & Econômico & $\mathbf{3 2}$ \\
\hline Atividade, Ação, Aula, Viagem, Prática & Plano da ação & $\mathbf{8 8}$ \\
\hline Recurso, Ferramenta, Instrumento & $\begin{array}{c}\text { Plano funcional- } \\
\text { instrumental }\end{array}$ & $\mathbf{1 3}$ \\
\hline Estratégia, Método, Processo & $\begin{array}{c}\text { Plano funcional- } \\
\text { projetivo }\end{array}$ & $\mathbf{9}$ \\
\hline
\end{tabular}

Fonte: Elaborado pelos autores, 2019.

Embora a dimensão econômica se faça presente, novamente se evidencia a significativa associação das características à dimensão pedagógico-educacional. Entretanto, ainda na perspectiva do delineamento global pretendido, um desdobramento analítico conduz ao estabelecimento de categorias representativas de vínculos estabelecidos com o TP, propiciando uma visão panorâmica abrangendo: as caracterizações (já submetidas a um processo de redução), o conjunto dos textos, assim como o conjunto dos Gêneros afetos a cada uma dessas categorias. São elas: Escola (como instituição formal de educação), Conteúdos curriculares, Deslocamento (que se mostram como tópicos centrais da categorização), Processo de ensino-aprendizagem (didático-pedagógico), Processo educativo-formativo (considerado o sentido mais amplo da palavra «educação»), Processo formativo-profissional, Mercado turístico e Gestão do destino turístico.

A título ilustrativo, indicam-se, na sequência, algumas das características diferenciadoras presentes nos textos vinculadas a essas categorias.

- Escola: Direcionamento às escolas; Início e término na escola; Organização pela escola com colaboração de empresas especializadas (citação); Realização em diversas instituições de ensino; Utilização pelas escolas em suas atividades educativas.

- Conteúdos curriculares: Complementação de conhecimento abordado em sala de aula (citação); Garantia de aprendizagem além das matérias.

- Deslocamento: Concretização por saída a campo; Aula-passeio; Desenvolvimento fora do ambiente físico restrito da sala de aula (espaço não usual/convencional); Deslocamento motivado pelo conhecer, compreender e interagir; Envolvimento de um 
tipo de deslocamento (viagem, visita, passeio, acampamento...) (citação); Realização nos arredores da escola, pela cidade ou região rural.

- Processo de ensino-aprendizagem: Promoção de aprendizagem significativa (dos conteúdos trabalhados previamente em sala de aula); Quebra da rotina escolar (tempo/ espaço); Suscitação de questionamentos; Ultrapassagem das amarras da mesmice; União do ensino com turismo (aluno assume temporariamente o papel de turista).

- Processo educativo-formativo: Construção de conhecimento, agregando valores que serão relevantes para a formação do aluno de forma pessoal e pedagógica; Desenvolvimento integral do sujeito; Despertar da consciência turística como parte integrante da consciência cidadã; Garantia de aprendizagem de valores (respeito) e de atitudes; Preparação para o viver em sociedade e para o exercício da cidadania; Reafirmação, através da vivência, de valores de ordem social, cultural e ambiental.

- Processo formativo-profissional: Importância para a formação dos futuros profissionais.

- Mercado turístico: Apresentação como nicho de mercado; Comercialização de produtos junto a escolas; Desenvolvimento dentro da estrutura do turismo convencional (transportes, hospedagem, alimentação, etc.); Enfrentamento à sazonalidade do turismo tradicional; Estímulo a agências específicas; Mercado relativamente recente no Brasil; Operação por agências especializadas, para escolas; Oportunidade de negócios capaz de gerar emprego e renda; Produtos personalizados e elaborados sob medida; Realização no período letivo e não no período de férias; Requerimento às agências de procedimentos e cuidados diferentes das demais modalidades.

- Gestão do destino turístico: Alternativa para os municípios direcionarem a atividade turística; Atendimento dos objetivos de desenvolvimento econômico e sociocultural da comunidade receptora; Crescimento econômico de pequenas localidades; Desenvolvimento da atividade com base local anteriormente não passível de ser utilizado como destino turístico; Planejamento/implantação e monitoramento realizado pelo município de acordo com as políticas regional, estadual e nacional; Possibilidade de exploração pedagógica de uma comunidade na conformação da oferta.

Esse delineamento mostra uma congruência com a distribuição das características nos planos estabelecidos (ou unidades ideativas) para encaminhamento das análises anteriores relativamente aos Gêneros atribuídos no processo definitório. Observa-se que, no Plano da Ação, concentra-se, com forte incidência, a dimensão pedagógico-educativa, estendida aos Planos sob o ângulo funcional: Funcional-projetivo e Funcional-instrumental. No outro polo, está o Plano econômico abrangendo particularmente o conjunto de características que dizem respeito ao mercado turístico e à gestão do destino turístico.

No entanto, objetivando dar maior precisão a essa visão panorâmica, no sentido de tentar esboçar uma definição conceitual de TP que possa expressar convergências das autorias, faz-se pertinente voltar o olhar à distribuição dessas características no conjunto dos textos, associadas ao gênero de maior incidência. Tendo, pois, por referência um percentual de alto a médio de incidências de gêneros e características a que se atribuiu o estatuto de estruturantes no conjunto dos 12 textos iniciais ( $100 \%$ a $50 \%$ de incidências), o processo possibilitou a formulação de uma definição de TP para a qual convergiu o conjunto de autorias. Face aos percentuais de incidência, pode-se atribuir às três primeiras características o status de 
estruturantes da definição conceitual, as quais são complementadas hierarquicamente pelas características presentes em 8,7 e 6 textos, e suplementadas por aquelas com menor representatividade (5, 4 e 3 textos), - o que o Quadro 4 permite sinteticamente visualizar.

Quadro 4. Esboço de definição conceitual de Turismo pedagógico construído a partir das análises dos textos constitutivos do corpus da pesquisa

\begin{tabular}{|c|c|c|c|}
\hline Termo & Cópula & Gênero & Características diferenciadoras/Natureza \\
\hline \multirow[t]{9}{*}{$\begin{array}{l}\text { Turismo peda- } \\
\text { gógico }\end{array}$} & \multirow[t]{9}{*}{ é (uma) } & \multirow{9}{*}{$\begin{array}{c}\text { atividade/ } \\
\text { prática pedagógica/ } \\
\text { educativa/ } \\
\text { educacional (que) }\end{array}$} & $\begin{array}{l}\text { envolve um tipo de deslocamento (viagem/ } \\
\text { visita/ passeio/ excursão) - Estruturante }\end{array}$ \\
\hline & & & $\begin{array}{l}\text { promove interação com o meio, vivências/ } \\
\text { experiências e conhecimento de espaços no- } \\
\text { vos - Estruturante }\end{array}$ \\
\hline & & & $\begin{array}{l}\text { promove aprendizagem na prática do que foi } \\
\text { visto (conteúdos) teoricamente em sala de } \\
\text { aula - Estruturante }\end{array}$ \\
\hline & & & $\begin{array}{l}\text { é preparada/organizada com fins educacionais } \\
\text { (não é um simples passeio, uma viagem } \\
\text { convencional, sem fins de lazer) - Comple- } \\
\text { mentar }\end{array}$ \\
\hline & & & tem caráter prazeroso - Complementar \\
\hline & & & $\begin{array}{l}\text { promove construção do conhecimento - Com- } \\
\text { plementar }\end{array}$ \\
\hline & & & $\begin{array}{l}\text { contribui para a leitura/ valorização/ preserva- } \\
\text { ção da cultura local e para o desenvolvimento } \\
\text { social - Suplementar }\end{array}$ \\
\hline & & & $\begin{array}{l}\text { facilita/melhora e amplia as condições de } \\
\text { aprendizagem - Suplementar }\end{array}$ \\
\hline & & & assume dimensão lúdica - Suplementar \\
\hline
\end{tabular}

Fonte: LIMA, 2014.

Uma observação aqui cabe ser feita. Ao longo do processo definitório, identificam-se deslizamentos conceituais expressos quer na atribuição de Gêneros (diferentes entre si, inclusive dentro do mesmo texto), quer na multiplicidade de características, as quais nem sempre apresentam coerência entre si ou em relação ao Gênero a que correspondem; quer na configuração do mesmo elemento/aspecto, ora como Gênero, ora como característica; quer no posicionamento do Gênero e das características perspectivados, ora desde a dimensão educativa, ora desde a dimensão turística.

\section{SÍNTESE INTERPRETATIVA: CRUZANDO RESULTADOS E PERSPECTIVAS TEÓRICAS}

Tomando por referência o percurso analítico até aqui realizado, já é possível retornar ao cerne do objetivo da pesquisa, ou seja, identificar/explicitar, no recorte temporal e espacial metodologicamente estabelecido, configurações conceituais que assume a denominação «TP» 
em proposições teóricas ou teórico-práticas presentes (e acessadas) na literatura científica brasileira (em que é tematizado o TP), considerando, de um lado, abordagens conceituais de turismo e, de outro, relações que se estabelecem entre modelos epistemológicos e pedagógicos. Em outras palavras, buscar responder a duas questões: Que turismo é esse subjacente ao binômio "TP» a que se referem as autorias? De igual forma: que concepções epistemológico-pedagógicas estariam subjacentes à definição conceitual construída? É para essa direção que se volta a sequência das reflexões.

\subsection{Que pedagógico é esse subjacente ao binômio «Turismo pedagógico»?}

Face a essa questão, destacam-se, nos artigos, os gêneros «atividade» e "prática» cunhados pelos adjetivos «pedagógica» / "educativa» / "educacional». As características diferenciadoras sublinham: o envolvimento de algum tipo de deslocamento (vetor principal do processo ensino-aprendizagem); a promoção de interação com o meio; de vivências/experiências; de conhecimento de espaços novos; de aprendizagem, na prática (fora da escola), dos conteúdos curriculares vistos teoricamente em sala de aula.

Gêneros e características inserem, em passagens argumentativas ou narrativas, o TP no universo da educação formal, trazendo, na perspectiva do processo de ensino-aprendizagem, elementos discursivos aproximativos de uma prática relacional que estaria afinada com supostos do construtivismo e do sociointeracionismo (aos quais estariam relacionadas menções à interação com o meio, à construção de conhecimento, à visão crítica, entre outras) e assim, sob o prisma da ciência, aproximativos de uma racionalidade crítica afeta ao paradigma científico contemporâneo, portanto em contraposição ao paradigma da ciência moderna.

Cabe aqui lembrar, juntamente com Köche (2010) que, em distintos momentos históricos o conhecimento científico foi construído por diferentes formas e sustentado por diferentes pressupostos epistemológicos, metafísicos e cosmológicos, resultando em rupturas paradigmáticas.

Kuhn (2003, p.38) destaca que "para ser aceita como paradigma, uma teoria deve parecer melhor que suas competidoras, mas não precisa (e de fato isso nunca acontece) explicar todos os fatos com os quais pode ser confrontada». Ainda segundo o mesmo autor (2003, p. 44), «na ciência, um paradigma raramente é suscetível de reprodução o paradigma é um objeto a ser melhor articulado e precisado em condições novas ou mais rigorosas».

Por conseguinte, o alinhamento com a ciência contemporânea implica distinções com relação à ciência moderna, entre outros aspectos, referentemente à relação sujeito-objeto, ao conceito de ciência e a seus resultados, como dá conta o Quadro 5. 
Quadro 5. Características divergentes entre o Paradigma da Ciência Moderna e o Paradigma da Ciência Contemporânea

\begin{tabular}{|l|l|l|}
\hline \multicolumn{1}{|c|}{ Características } & \multicolumn{1}{|c|}{ Ciência Moderna } & \multicolumn{1}{c|}{ Ciência Contemporânea } \\
\hline Relação Sujeito - Objeto & $\begin{array}{l}\text { Separação entre sujeito que } \\
\text { observa e o objeto a ser } \\
\text { observado: eliminação da } \\
\text { subjetividade. Visão empirista. }\end{array}$ & $\begin{array}{l}\text { Interação entre o sujeito } \\
\text { que observa e o objeto a ser } \\
\text { observado. Visão racionalista- } \\
\text { crítica. }\end{array}$ \\
\hline Conceito de Ciência & $\begin{array}{l}\text { Reduzida às relações } \\
\text { quantitativas existentes entre } \\
\text { as propriedades dos fenômenos } \\
\text { e análise de suas respostas. } \\
\text { Teorias como descrições } \\
\text { exatas, objetivas, comprovadas, } \\
\text { absolutas, previsíveis. Metódica, } \\
\text { controlável e destituída de } \\
\text { subjetividade para quem a } \\
\text { produz. }\end{array}$ & $\begin{array}{l}\text { Aberta a novas perspectivas } \\
\text { sobre o mesmo objeto } \\
\text { investigado, pluralismo teórico, } \\
\text { Imprevisível, conjectural e } \\
\text { intersubjetiva. Teorias como } \\
\text { interpretações conjecturais. }\end{array}$ \\
\hline Resultados & $\begin{array}{l}\text { Verdades e Certezas (descrições } \\
\text { matemáticas do real). Progresso } \\
\text { por acumulação de certezas. }\end{array}$ & $\begin{array}{l}\text { Aproximações da realidade, } \\
\text { ou seja, teorias como } \\
\text { representações do real, } \\
\text { interpretações. }\end{array}$ \\
\hline $\begin{array}{l}\text { Teorias como descrição fiel do } \\
\text { real. }\end{array}$ & \\
\hline
\end{tabular}

Fonte: Köche, 2010. Adaptado.

Atualmente coexistem dois modelos epistemológico-pedagógicos que se destacam no panorama educacional: o chamado tradicional (conservador) e o construtivista (inovador). Embora, como ressalta Behrens (1999), o principal objetivo - e também desafio da educação - seja encontrar novos rumos e caminhos consistentes com a realidade e o contexto contemporâneo, a transição do modelo tradicional para o construtivista ainda se mostra uma questão não resolvida. Buscando respaldo particularmente no desenho reflexivo de Becker (2012), estariam aí implícitas, contrastivamente, de um lado, relações entre empirismo (que fundamenta o paradigma newtoniano-cartesiano, relativo à Ciência Moderna) e pedagogia diretiva; e, de outro, entre construtivismo e pedagogia relacional.

«No empirismo, o conhecimento vem do objeto, que o sujeito recebe passivamente através das sensações ou experiências», diz Matui (1995, p. 39). Partindo desse princípio, o sujeito torna-se então o elemento conhecedor, e o objeto, tudo aquilo que não é sujeito. Nesse contexto, o indivíduo é determinado pelos meios físico e social. No âmbito escolar, a pedagogia diretiva, de base empirista, conduz a uma prática pedagógica em que os conhecimentos são considerados absolutos e inquestionáveis, providos pelo meio e transmitidos aos indivíduos por intermédio do professor.

O modelo pedagógico relacional, conforme pontuado por Becker (2012), encontra suas bases no Construtivismo, aqui remetendo, particularmente, à Epistemologia Genética piagetiana, a qual, opondo-se à ideia de um universo de conhecimento dado, propõe que o sujeito, 
cujas estruturas internas resultam de uma construção efetiva e contínua, constrói seu conhecimento na interação, tanto com o meio físico quanto com o meio social, de sorte que se tem a proposição de uma epistemologia que «é naturalista sem ser positivista, que coloca em evidência a atividade do sujeito sem ser idealista, que se apóia igualmente no objeto ao mesmo tempo que o considera um limite e que, sobretudo, vê no conhecimento uma construção contínua» (Piaget, 1983, p. 5). Na concepção construtivista, assinala Matui (1995), o sujeito e o objeto não são estruturas separadas, mas constituem uma só estrutura, pela interação recíproca: o sujeito (sujeito histórico) não existindo sem o objeto (meio), nem este sem aquele.

Assinalando a perspectiva sociointeracionista na construção do conhecimento, Vygotsky (1979) ressalta que as funções mentais superiores são construídas justamente na interação social, na qual - contando com a necessária mediação - o sujeito realiza processos de internalização; estes compreendidos como operações de reconstrução interna de operações ou atividades externas, num percurso que evolui desde o exterior até uma operação interior.

Entretanto, da análise de Gêneros e características diferenciadoras, não obstante, discursivamente, as manifestações das autorias estarem apontando para a racionalidade da ciência contemporânea, o que se depreende é um não descolamento do modelo epistemológico empirista. A possibilidade de concretização da ação pedagógica nas perspectivas construtivista e sociointeracionista mostra-se como prerrogativa apenas do estar fora da escola.

Categoricamente, o processo de aprendizagem na escola é definido como o lugar do teórico, diametralmente oposto àquele realizado fora dela (o lugar da prática, do real material, concreto, da realidade mostrada). O conhecimento passa a «vir do objeto» a partir de uma experiência sensível, impondo-se ao sujeito, que não a significa. O espaço intraescolar apresenta-se como esvaziado do caráter de meio social, no qual aluno e professor também se afiguram esvaziados de sua condição de sujeitos epistêmicos e sociais.

Para, além disso, resultados positivos são tomados como consequências necessárias, distanciando-se das marcas da singularidade de cada sujeito, instalando-se um conflito entre o tom categórico, determinista das verbalizações e a essência potencializadora da pedagogia relacional na promoção da construção de conhecimento por um sujeito portador de uma história - o que torna único e imprevisível cada processo por ele realizado. Revela-se ainda um tangenciamento do papel do mediador, essencial na pedagogia relacional, abrindo-se espaço à manutenção da perspectiva pedagógica diretiva.

\subsection{Que turismo é esse subjacente ao binômio «Turismo pedagógico»?}

Na resposta a essa questão, conforme denotam os Gêneros e o conjunto de características diferenciadoras correspondentes, o TP é abordado, na dimensão econômica, como um segmento de mercado destinado às instituições de ensino (cliente) para o desenvolvimento de suas atividades educativo-pedagógicas, disponibilizando sua infraestrutura, seus serviços e equipamentos e contribuindo também para fazer frente à sazonalidade do turismo convencional. 
Segundo o Sistema de Turismo (SISTUR) proposto por Beni (2008, p. 163), «no estudo do mercado existem três questões centrais: o que produzir, como produzir e para quem produzir». Essas decisões fazem parte do conjunto das ações operacionais do SISTUR, compreendido pelos subsistemas de oferta, mercado, demanda, numa relação determinante de produção, distribuição e consumo. Nos termos do pesquisador (2008, p. 167), «para cada produto turístico, pode-se identificar um tipo de mercado, real e potencial» (No caso do TP, a escola é o mercado potencial; entretanto, ela só se tornará um mercado real quando demandar o serviço). Acrescenta ainda o autor (2008, p. 26) que, em se tratando do turismo, «há uma característica ainda mais marcante: o produto turístico é produzido e consumido no mesmo local, e o consumidor é que se desloca para a área de consumo, portanto rigorosamente dentro do sistema».

A diversidade da oferta turística em relação às tendências da demanda, entre outros fatores, ocasiona a expansão desse mercado, o que suscita o surgimento e a consolidação de numerosos segmentos turísticos. A segmentação turística, assim, pode ser entendida como "uma estratégia de marketing que divide os consumidores em segmentos ou subsegmentos, de acordo com critérios preestabelecidos na busca da otimização dos recursos existentes nas relações entre a demanda e a oferta» (Lohmann, Panosso Netto, 2012, p. 170).

Nesse sentido, o TP é entendido como um segmento de mercado destinado às instituições de ensino (cliente) para o desenvolvimento de suas atividades educativas, no qual o turismo disponibiliza sua infraestrutura, seus serviços e equipamentos para facilitar o alcance dos objetivos propostos; em outras palavras, para satisfazer as necessidades e desejos de seus clientes e de seus consumidores.

Assim, o termo «TP» focalizado na dimensão mercadológica, ou seja, como segmento turístico, é organizado e comercializado pelas agências de viagens e turismo junto às instituições de ensino (escolas), de acordo com os projetos pedagógicos dessas. A agência é a responsável pela contratação dos serviços, equipamentos necessários para a viagem, operacionalizando a atividade. Relembrem-se aqui características definitórias elaboradas a partir de menções presentes nos textos e retomadas nos diagramas analíticos: "segmento de mercado na atividade turística, voltado às escolas»; "segmento turístico que se apresenta como nicho de mercado capaz de fazer frente à sazonalidade do turismo tradicional»; "tipo de serviço prestado por agências às escolas»; "tipo de turismo desenvolvido dentro das estruturas de um turismo convencional: transportes, hospedagem, alimentação, serviços de apoio, etc.; que serve às escolas em suas atividades educativas que envolvem viagens».

Sob essa perspectiva e, conforme constante dos artigos em exame, o segmento do mercado turístico denominado "TP» se apresenta como: «uma alternativa para o crescimento da economia de pequenas localidades, fazendo surgir novas oportunidades de negócios, gerando emprego e renda e proporcionando uma melhor qualidade de vida para a comunidade receptora»; "principal alternativa para o município direcionar a atividade turística, oferecendo qualidade às comunidades locais»; uma possibilidade de "desenvolver a atividade com base local em locais anteriormente não passíveis de serem utilizados como destinos turísticos» e "de atender aos objetivos de desenvolvimento sociocultural da comunidade receptora» (fragmentos extraídos dos diagramas analíticos). 
Diante das considerações acima, a primeira resposta a ser dada à pergunta Que turismo é esse subjacente ao binômio "Turismo pedagógico»? seria aquela que o apresenta como uma atividade econômica dentro do sistema econômico, ou, segundo diria Beni (2008), uma atividade que se move na esfera do econômico, cabendo assim compreendê-la em uma perspectiva sistêmica. Na dinâmica desse sistema, se encontra o mercado nas suas relações de oferta e demanda, e de produção, distribuição e consumo. E é em função desse entendimento sobre o turismo, no viés econômico/mercadológico, que o TP se institui como um segmento de mercado do turismo.

Ressalte-se, porém, que tais respostas permitem trazer à reflexão o próprio conceito de TP, partindo-se da constituição morfológica do binômio (Turismo = substantivo-núcleo). Se considerado circunstancialmente pedagógico, o turismo seria uma prática fundamentalmente consubstanciada pela viagem (pelo deslocamento) empreendida(o), e o status de pedagógico Ihe seria atribuído somente quando vinculado à escola. Haveria aí uma espécie de «nucleação invertida» do binômio, na medida em que a escola (espaço tradicional do pedagógico) se serve do turismo (deslocamento/viagem para fora da escola) em suas atividades curriculares. O TP reforça-se assim como segmento de mercado.

Por outro lado, num exercício reflexivo pautado pela relação binomial «substantivo-adjetivo" e pelo intuito de pôr em análise as conclusões até aqui construídas, uma outra resposta, para além daquelas formuladas com base nos textos examinados, mostra-se possível a partir de uma leitura do turismo em que o "pedagógico», no sentido amplo de acionamento de transformações nos sujeitos da experiência, portanto, de promoção de aprendizagens, institui-se como uma característica substantiva.

Inserindo o turismo no âmbito dos fenômenos humano-sociais e destacando processos interativos de natureza objetiva, subjetiva e intersubjetiva, Perazzolo, Santos e Pereira (2013, p. 142, tradução nossa), dentre outras formulações teóricas, propõem, numa perspectiva psicoantropológica, a compreensão do turismo como expressão do desejo humano de conhecer, como uma das formas através das quais o ser humano daria destino à «pulsão de conhecer» ${ }^{4}$, voltando o olhar ao universo desconhecido, ao fora de si, a outra coisa, ao que não pode ser encontrado onde se está.

O turismo conteria em si a latência para conhecer e o aprender, sendo o saber procurado construído na relação, por meio de movimentos de interação constitutivos do fenômeno do acolhimento (aquele em que, na dinâmica relacional, o acolhedor se transforma em acoIhido, e o acolhido, em acolhedor). Essa dimensão relacional, própria ao acolhimento, tem como propriedade a possibilidade de transformar os sujeitos «em direções que acabam por conferir uma outra tonalidade a toda configuração mental e, consequentemente, por transformar a percepção que os sujeitos têm de sua casa, seus produtos, bens materiais/imateriais e sobre si mesmo» (Perazzolo, Santos e Pereira, 2013, p. 149, tradução nossa).

4. Na proposição das autoras (2013, p.142), trata-se da pulsão de conhecer/experenciar, «na sua forma mais primária, tal como apresentada no conceito de pulsão epistemofílica proposto por Freud (1992) no texto «Três ensaios para uma teoria sexual», de 1926. O tema é também abordado à luz das contribuições lacanianas, particularmente na perspectiva da pulsão escópica.» (Tradução nossa). 
Assim, se genuíno, o acolhimento carrega o potencial pedagógico de ser agente de aprendizagens, instaurando-se como um dos elementos fundantes do turismo e levando a compreendê-lo como um fenômeno pedagógico em si. Sob esse ângulo, o pedagógico não se configura como algo desejável, circunstancial, adjetivo, restrito a algumas situações, mas como uma qualidade intrínseca ao turismo, necessária, substantiva, presente em todas as situações, independentemente do grau em que se efetive. Sob essa perspectiva, adjetivar o turismo como pedagógico corresponderia a um pleonasmo, não se justificando, pois, a manutenção do binômio.

Essas reflexões, não circunscritas aos textos analisados, levam então a construir uma resposta à pergunta "Que turismo é esse subjacente ao binômio TP?», na qual esse seria entendido como um fenômeno humano-social que pressupõe um deslocamento realizado por um sujeito motivado/mobilizado para vivenciar/conhecer o novo, o outro, em experiências relacionais no ou fora do local de experiência cotidiana, constituindo-se um espaço de contínua construção, formação e transformação do sujeito, que passa a ter novas percepções do outro e de si mesmo. Em outras palavras, um espaço de aprendizagens em que o pedagógico se configura, substantivamente, como propriedade do turismo.

Ora, na opção da escola por incluir em suas atividades educativo-pedagógicas esse(a) turismo/viagem/deslocamento, haveria, pois, o reconhecimento dos traços da potencialidade pedagógica intrínseca ao turismo, a qual «autorizaria» a atribuição das características diferenciadoras que lhe foram conferidas. Diante dessas considerações, em tese, a forma que se apresenta como mais adequada para nomear essa prática seria Atividade pedagógica pelo turismo. Nela estaria bem marcada a «nucleação invertida» e, ao mesmo tempo, a não incompatibilização dos resultados a que levaram os dois caminhos analíticos percorridos.

\section{NA DIREÇÃO DE CONSIDERAÇÕES FINAIS}

Para além das incursões reflexivas já realizadas sobre o conceito de turismo e sobre a qualificação "pedagógico» no binômio "TP», não se poderia aqui deixar de destacar o fato de que os textos examinados (exceção feita aos que trazem uma abordagem mercadológica e aos que buscam revisar a literatura sobre o binômio) preconizam essa atividade pedagógica pelo turismo como alternativa para fazer frente aos processos e rotinas que se encontram tradicionalmente na realidade escolar.

Por meio deles, parece possível hipotetizar uma mensagem que lhes estaria sendo subliminar: a de que realizar atividades pedagógicas extramuros por si só se configuraria em condição essencial para que a educação formal cumpra seu papel. Sem que se esteja pondo em discussão aspectos positivos dessa prática, haveria aparente desconsideração tácita de que a escola, intramuros, também se constitui em um meio social para o desenvolvimento de processos interativos, construção e (re)significação de conhecimento, de desenvolvimento de valores humano-sociais, de socialização etc. e de que os exercícios de prática teórica, quando adequada e pertinentemente realizados, com as suas consequentes descobertas, podem igualmente tornar-se fontes de prazer (o prazer intelectual). Curiosamente, um dos textos descreve atividades desenvolvidas em sala de aula antes e após a saída da escola, afinadas com 
o modelo pedagógico construtivista, porém essas não são identificadas como tal, talvez pelo fato de terem sido realizadas no espaço escolar.

Da dimensão econômico-mercadológica para a qual também apontaram Gêneros e características definitórias, emergiu o TP como um segmento de mercado do turismo, que se concretiza na relação com a escola (nisso estando novamente implícito o caráter contingencial do pedagógico). Tem-se uma relação de oferta (produto) e demanda (escola). Nessa outra ótica, o turismo está a serviço da escola - o que distingue esse segmento mercadológico de outros «não pedagógicos» - associado a elementos/aspectos de gestão, quando se destacaria, por esse meio, a possibilidade de fomento do desenvolvimento econômico das comunidades locais. O conceito de turismo que se depreende é o de uma atividade econômico-mercadológica dentro do sistema econômico, compreendida numa perspectiva sistêmica.

Independentemente de o binômio "TP» poder ser considerado um pleonasmo, há que se ter presente que, na lógica do mercado, os segmentos têm de ser demarcados, razão pela qual não se está propondo o abandono do termo. O que estas ponderações conduzem a refletir é que, se o status de pedagógico deixasse de ser conferido pela destinação exclusiva ao público escolar, seria possível ampliar/redimensionar o próprio segmento. Isso significa dizer que, se o pedagógico for entendido como promotor de aprendizagem em sentido amplo, novos horizontes mercadológicos poderão ser abertos, mantendo-se, porém, primariamente, o foco no pedagógico. Dito de outra forma, o TP poderia ser estendido a outros públicos além daqueles provenientes da educação formal e a outras e múltiplas finalidades além da aprendizagem de conteúdos curriculares. Isso, aliás, é sinalizado por autores como Moreira, Avilés e Valle (2009), citados em um dos textos, para os quais se teria um ramo de turismo especializado em viagens, nas quais os próprios turistas se organizam com o propósito não só de conhecer o lugar, mas também com o de aprender sobre e compreender o local visitado, sem que a aprendizagem decorra necessariamente de um plano estrito e formal, mas, ao contrário, ocorrendo dentro de um espectro amplo de educação não formal, utilizando toda a gama de opções de aprendizagens possibilitada por esse segmento, assim como os meios necessários para que o turista se envolva nesses espaços.

Da mesma forma, se poderia pensar em desdobramentos do foco pedagógico agregando-Ihe outras especificações que propiciassem direcionamentos mais precisos em relação a interesses de demanda, à inclusão dessa lógica em locais turísticos ainda sem vocação definida, ou, até mesmo, em locais com vocação definida afeta a outros segmentos, ampliando assim suas possibilidades de oferta.

No outro pólo, o da educação formal, ao terem em conta o que estas reflexões conceituais trazem à tona no que se refere à realização de atividades pedagógicas pelo turismo, as instituições de ensino poderiam nelas encontrar outros subsídios para avaliar criticamente suas práticas, suas opções relativas a espaços, períodos, duração, equipe, planejamento, podendo vir a potencializar a latência pedagógica do turismo e, então, enriquecer os processos de aprendizagem desejados.

Uma última observação acerca de eventuais contribuições que estas reflexões possam vir a aportar diz respeito a uma necessidade, percebida no início da revisão de literatura, de 
aprimoramento de definição de descritores de pesquisa que possam refinar as buscas bibliográficas, facilitando o acesso ao conhecimento científico produzido nesse campo de estudo. Considerando a consensualidade em relação ao uso do binômio "Turismo pedagógico» no âmbito do mercado, como também no da educação formal, com os desdobramentos do já referido foco primário sobre o pedagógico, talvez se possa lograr pensar descritores que tenham como elemento nuclear «TP», circunstanciado por diferentes especificações que atribuam maior precisão ao binômio, sem que isso signifique apenas um jogo semântico. Ter-se-iam denominações como TP em meio rural, TP industrial, TP ambiental, TP cultural, TP religioso, etc.

Por outro lado, se o recorte metodológico encaminhou à produção bibliográfica brasileira, tem-se presente que as reflexões realizadas, a estratégia metodológica utilizada e os resultados obtidos não necessariamente estariam restritos ao país, porquanto poderiam constituir-se em um dentre outros referentes para proposição e desenvolvimento de pesquisas voltadas a essa temática em outros territórios geográficos.

Ressalte-se ainda o entendimento da relevância do exercício analítico conceitual aqui realizado e submetido à crítica intersubjetiva, particularmente quando se considera a Academia como um lugar privilegiado de vigilância epistemológica, rompendo assim eventuais inércias reflexivas.

\section{REFERÊNCIAS}

Alves, K. dos S. (2014). O turismo pedagógico como indutor de lugares identitários para reconhecer, interpretar e preservar. Revista Turismo \& Desenvolvimento, 4(21/22), 483-491. Recuperado de: http://revistas.ua.pt/index.php/rtd/article/view/8877

Ansarah, M. G. dos R. (2005). Turismo e segmentação de mercado: novos segmentos. En: L. G. G. Trigo. Análises Regionais e Globais do Turismo Brasileiro (pp.285-299). São Paulo: Roca.

Becker, F. (2012). Educação e construção do conhecimento. 2. ed. Porto Alegre: Penso.

Behrens, M. A. (1999). A prática pedagógica e o paradigma emergente. Curitiba: Champagnat. Beni, M. C. (2008). Análise estrutural do Turismo. 13. ed. São Paulo: SENAC.

Bonfim, M. V. de S. (2010). Por uma pedagogia diferenciada: uma reflexão acerca do turismo pedagógico como prática educativa. Revista Turismo Visão e Ação-Eletrônica, 12(1), 114-129. Recuperado de: https://www6.univali.br/seer/index.php/rtva/article/view/ $1127 / 1511$

Carvalho, A. B. P.; Escobar, L. O. C.; Cademartori, C. V. (2017). A educação ambiental através do turismo pedagógico. Applied Tourism, 2 (3), 26-36. Recuperado de: https://siaiap32. univali.br/seer/index.php/iith/article/view/11840/pdf

Garcia, O. M. (2006). Comunicação em prosa moderna: aprenda a escrever, aprendendo a pensar. 26. ed. Rio de Janeiro: Editora FGV.

Gomes, D. S.; Mota, K. M.; Perinotto, A. R. C. (2012). Turismo pedagógico como ferramenta de educação patrimonial: a visão dos professores de História em um colégio estadual de Parnaíba (Piauí, Brasil). Revista Turismo e Sociedade, 5(1), 82-103. Recuperado de: http://ojs.c3sl.ufpr.br/ojs2/index.php/turismo/article/view/25326/17713 
Gonçalves, J. de S.; Serafim, L. S. (2006). O desenvolvimento de um novo produto turístico: o turismo pedagógico. En: seminário da Associação Nacional de Pesquisa e Pós-graduação em Turismo - ANPTUR, 3. Anais eletrônicos... Recuperado de: https://www.ucs.br/ucs/ tplSemMenus/eventos/seminarios semintur/semin tur_4/arquivos 4 seminario/ GT11-A5.pdf

Ito, C. A. (2010). Turismo Pedagógico: Relato de Experiência no Ensino Fundamental. En: Seminário de Pesquisa em Turismo do Mercosul - SEMINTUR, 6. Anais eletrônicos... Caxias do Sul: UCS, 2010. Recuperado de: https://www.ucs.br/ucs/eventos/seminarios semintur/semin tur 6/arquivos/01/Turismo\%20Pedagogico\%20Relato\%20 de\%20Experiencia\%20no\%20Ensino\%20Fundamental.pdf

Köche, J. C. (2010). Fundamentos de Metodologia Científica: Teoria da ciência e iniciação à pesquisa. 27. ed. Petrópolis: Vozes.

Kuhn, T. S. (2003) A estrutura das revoluções cientificas. 8. ed. São Paulo: Perspectica.

Lima, F. de (2014). Incursões reflexivas sobre o conceito de Turismo e a qualificação "Pedagógico" no binômio "Turismo Pedagógico". Dissertação de mestrado, Universidade de Caxias do Sul, Caxias do sul, Rio Grande do Sul, Brasil. Recuperado de: https://repositorio.ucs.br/xmlui/bitstream/handle/11338/840/Dissertacao\%20 Francielle\%20de\%20Lima.pdf?sequence $=1$ \&isAllowed $=y$

Lima, F. de; Santos M. M. C; Rejowski, M. (2012) Turismo Pedagógico e binômios considerados afins: um percurso de revisão de literatura. In: SEMINÁRIO DE PESQUISA EM TURISMO DO MERCOSUL - SEMINTUR, 7. Anais eletrônicos... Caxias do Sul. Recuperado de: https://www.ucs.br/ucs/eventos/seminarios semintur/semin tur 7/arquivos/01/09 Lima Santos Rejowski.pdf

Lohmann, G.; Panosso Netto, A. (2012). Teoria do Turismo: conceitos, modelos e sistemas. 2. ed. São Paulo: Aleph.

Matos, F. de C. (2012). Turismo Pedagógico: o estudo do meio como ferramenta fomentadora do currículo escolar. In: Seminário de Pesquisa em Turismo do Mercosul - SEMINTUR, 7. Anais eletrônicos... Recuperado de: https://www.ucs.br/ucs/eventos/seminarios semintur/semin tur 7/arquivos/01/01 Mattos.pdf

Matui, J. (1995). Construtivismo: teoria construtivista sócio-histórica aplicada ao ensino. São Paulo: Moderna.

Moraes, C. C. de A. (2006). Turismo Pedagógico em Quilombos: considerações sobre a formação de uma comunidade turística. In: Seminário de Pesquisa em Turismo do MERCOSUL, 4. Anais eletrônicos... Recuperado de: http://www.ucs.br/ucs/tplSemMenus/posgraduacao/strictosensu/Turismo/seminarios/seminario 4/arquivos 4 seminario/GT10-4.pdf

Morais, J. P.; Maia, J. S. da S. (2005). A prática do Turismo pedagógico: um estudo de caso na creche EMEI Mário de Andrade de Ourinhos. Revista Global Tourism-Turismo e Educação. Recuperado de: http://www.periodicodeTurismo.com.br/site/artigo/viewArtigo.php?codigo=38\&titulo=A\%20PRÁTICA\%20DO\%20TURISMO\%20PEDAGÓGICO:\%20UM\%20 ESTUDO\%20DE\%20CASO\%20NA\%20CRECHE\%20E.M.E.I.\%20MÁRIO\%20DE\%20 ANDRADE. Acesso em: 24 maio 2011.

Peccatiello, A. F. O. (2005). Turismo Pedagógico como uma estratégia de ensino-aprendizagem sob a ótica dos Parâmetros Curriculares Nacionais - 3 느 Ciclos do Ensino Fundamental. Revista Global Tourism -Turismo e Educação. Recuperado de: http:// 
www.periodicodeTurismo.com.br/site/artigo/pdf/TURISMO\%20PEDAGÓGICO\%20 COMO\%20UMA\%20ESTRATÉGIA\%20DE\%20ENSINO-APRENDIZAGEM\%20SOB\%20 A\%20ÓPTICA\%20DOS\%20PARÂMETROS\%20CURRICULARES\%20NACIONAIS\%20-\%203%20E\%204\%20CICLOS\%20DO\%20ENSINO\%20FUNDAMENTAL.pdf

Perazzolo, O. A.; Santos, M. M. C.; Pereira, S. (2013). Dimensión relacional de la acogida. Revista Estudios y perspectivas em turismo, 22(1), 138-153. Recuperado de: http://www.scielo. org.ar/scielo.php?pid=S1851-17322013000100008\&script=sci arttext

Perinotto, A. R. C. (2008). Turismo pedagógico: uma ferramenta para educação ambiental. Caderno Virtual de Turismo, 8 (1), 100-103. Recuperado de: http://www.ivt.coppe. ufri.br/caderno/index.php?journal=caderno\&page=article\&op=view \&path\%5B\%$\underline{5 \mathrm{D}=261 \& \text { path\%5B } \% 5 \mathrm{D}=186}$

Piaget, J. (1983). A Epistemologia Genética. Tradução de Nathanael C. Caixeiro, Zilda Abujamra Daeir, Celia E.A. di Piero. 2. ed. São Paulo.

Raykil, E. B.; Raykil, C. (2005). Turismo pedagógico: uma interface diferencial no processo ensino aprendizagem. Revista Global Tourism - Turismo e Educação. Recuperado de: http://www.periodicodeTurismo.com.br/site/artigo/viewArtigo.php?codigo=40\&titulo=TURISMO\%20PEDAGÓGICO:\%20UMA\%20INTERFACE\%20DIFERENCIAL\%20NO\%20 PROCESSO\%20ENSINO\%20APRENDIZAGEM. Acesso em: 01 nov. 2011.

Ricoeur, P.; (1978). O conflito das interpretações: ensaios de hermenêutica. Rio de Janeiro: Imago.

Silva, I. de O.; Nascimento, M. C. D. (2006). Turismo pedagógico: uma estratégia para o ensino de história e educação patrimonial. En: Seminário da Associação Nacional de Pesquisa d Pós-Graduação de Turismo - ANPTUR, 3. Anais eletrônicos... Recuperado de:https:// www.ucs.br/ucs/tplSemMenus/eventos/seminarios_semintur/semin tur 4/arquivos 4 seminario/GT08-9.pdf

Silveira, C. R. F. D. da; Martins, P. C. S.; Sa Vieira, F. (2008). Turismo Pedagógico em Dourados / MS- Uma atividade educacional. En: Seminário de Pesquisa em Turismo do Mercosul - SEMINTUR, 5. Anais eletrônicos... Recuperado de: https://www.ucs.br/ucs/tplVSeminTur\%20/eventos/seminarios semintur/semin tur 5/trabalhos/arquivos/gt13-12. $\underline{\mathrm{pdf}}$

Tonini, H.; Ferreira, M. V.; Nunes, M. B. (2012). Turismo pedagógico na Restinga (Porto Alegre-RS). En: Seminário da Associação Nacional de Pesquisa e Pós-Graduação em Turismo - ANPTUR, 9. Anais eletrônicos... Recuperado de: https://www.anptur.org.br/ anais/anais/files/9/2.pdf

Valduga, V.; Fernandes, A. do R. A. (2016). Turismo pedagógico: uma práxis transdisciplinar entre turismo e a pedagogia. En: Seminário da Associação Nacional de Pesquisa e PósGraduação em Turismo - ANPTUR, 13. Anais eletrônicos... Recuperado de: https:// www.anptur.org.br/anais/anais/files/13/639.pdf

Vygotsky, L. S. (1979). Pensamento e linguagem. 42. ed. Lisboa: Antídoto. 